\title{
Balloon Kyphoplasty to Thoracic Vertebral Fracture with Postoperative Treatment Difficulty: A Case Report
}

\author{
Hiromitsu Takano, ${ }^{1,2}$, Hajime Kajihara ${ }^{1,2}$, Takatoshi Okuda ${ }^{2}$ \\ ${ }^{1}$ Department of Orthopedic Surgery, Koto Hospital, Tokyo, Japan \\ ${ }^{2}$ Department of Orthopedic Surgery, Juntendo University School of Medicine, Tokyo, Japan \\ Email: hrtakano@juntendo.ac.jp
}

How to cite this paper: Takano, H., Kajihara, H. and Okuda, T. (2020) Balloon Kyphoplasty to Thoracic Vertebral Fracture with Postoperative Treatment Difficulty: A Case Report. Open Journal of Orthopedics, 10, 295-302.

https://doi.org/10.4236/ojo.2020.1010030

Received: September 15, 2020

Accepted: October 25, 2020

Published: October 28, 2020

Copyright $\odot 2020$ by author(s) and Scientific Research Publishing Inc. This work is licensed under the Creative Commons Attribution International License (CC BY 4.0).

http://creativecommons.org/licenses/by/4.0/

\begin{abstract}
In this communication, we report our experience with a case of thoracic vertebral fracture which was treated by balloon kyphoplasty and which later developed an infection at the fracture site, causing treatment difficulty. The patient was a 74-year old female with a history of remitting seronegative symmetrical synovitis with pitting edema (RS3PE) syndrome as well as diabetes mellitus. She had been diagnosed with mycoplasma pneumonia as well as a fracture of the T12 vertebral and was admitted to the Department of Internal Medicine to receive medical/non-surgical treatment. Medical treatment was carried out and the pneumonia symptoms improved but getting out of bed was impossible due to the continuing of back pain. Therefore, T12 balloon kyphoplasty was performed in order to allow for early ambulation. Back pain started to improve immediately after surgery, but at 2 months after surgery, the back pain relapsed, and fever developed. Imaging tests revealed a vertebral osteolysis of T11-T12 and, as a measure against vertebral collapse due to postoperative infection or osteomyelitis of the thoracic spine, the feasibility of balloon kyphoplasty was considered. Antibiotic treatment was carried out, and when findings showed that the infection had resolved, posterior fusion (T9-L2) was performed using percutaneous pedicle screws. When balloon kyphoplasty for the treatment of a vertebral fracture is performed in an immunocompromised patient early after injury, the treatment needs to be chosen carefully, and the possibility of a latent vertebral osteomyelitis should be kept in mind.
\end{abstract}

\section{Keywords}

Vertebral Fracture, Balloon Kyphoplasty, Pyogenic Spondylitis 


\section{Introduction}

Balloon kyphoplasty is one of the treatment options for vertebral fractures with persistent pain, but nowadays, performing balloon kyphoplasty is at an early stage after the occurrence of a vertebral fracture has become increasingly common. In this communication, we report our experience with a case of thoracic vertebral fracture which was diagnosed and treated relatively early by balloon kyphoplasty, but the patient later developed an infection at the fracture site, leading to treatment difficulty. A discussion based on the literature is also provided.

\section{Case Report}

\subsection{History and Presentation}

Patient: 74-year old woman with a height of $161 \mathrm{~cm}$ and a body weight of 80 $\mathrm{kg}$.

Chief complaints: back pain and loss of appetite.

Personal history: remitting seronegative symmetrical synovitis with pitting edema (RS3PE) syndrome (treated with oral PSL $9 \mathrm{mg}$ for 4 years), diabetes mellitus.

History of the present illness: The patient was admitted in emergency to our hospital's Department of Internal Medicine for back pain and a loss of appetite, which had developed without any apparent contributing factors. The C-reactive protein (CRP) was $32.56 \mathrm{mg} / \mathrm{dL}$ and the white blood cell count (WBC) was as high as $11,880 / \mu \mathrm{L}$ (Table 1 ). In addition, there were infiltrative shadows in the bilateral lower lung fields and the mycoplasma antigen was positive; therefore, the patient was diagnosed with mycoplasma pneumonia. As for back pain, T2-weighted imaging (T2WI) in magnetic resonance imaging (MRI) and short tau inversion recovery sequence MRI (STIR) showed high signal intensity changes in T12; thus, the condition was diagnosed as a fracture of the T12 vertebral (Figure 1 and Figure 2). Non-surgical treatment was prioritized, and findings showed that the mycoplasma pneumonia improved. In the meantime, the patient developed a urinary tract infection; therefore, antibiotic treatment was carried out, and preoperative blood tests showed improvements as CRP levels reached $1.67 \mathrm{mg} / \mathrm{dL}$ and the WBC count decreased to $10,860 / \mu \mathrm{L}$ (Table 1 ).

Table 1. Clinical blood tests.

\begin{tabular}{ccccc}
\hline & CRP & WBC & ESR & Diagnosis \\
\hline First visit & $32.56 \mathrm{mg} / \mathrm{dL}$ & $11,880 / \mu \mathrm{L}$ & $100 \mathrm{~mm}$ & Mycoplasma pneumonia \\
Preoperative & $1.67 \mathrm{mg} / \mathrm{dL}$ & $10,860 / \mu \mathrm{L}$ & $59 \mathrm{~mm}$ & Urinary tract infection \\
Postoperative 2 months & $3.46 \mathrm{mg} / \mathrm{dL}$ & $9680 / \mu \mathrm{L}$ & $38 \mathrm{~mm}$ & Pyogenic spondylitis \\
Postoperative 4 months & $0.28 \mathrm{mg} / \mathrm{dL}$ & $7600 / \mu \mathrm{L}$ & $15 \mathrm{~mm}$ & \\
$\begin{array}{c}\text { Posterior fusion postoperative } \\
\text { 1 months }\end{array}$ & $0.24 \mathrm{mg} / \mathrm{dL}$ & $7900 / \mu \mathrm{L}$ & $9 \mathrm{~mm}$ & \\
\hline
\end{tabular}




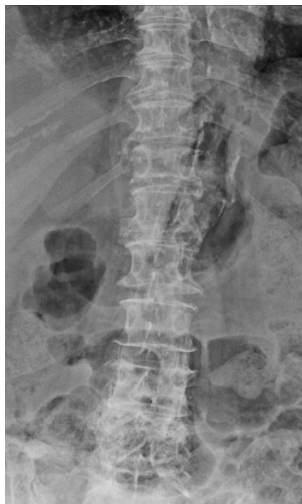

(a)

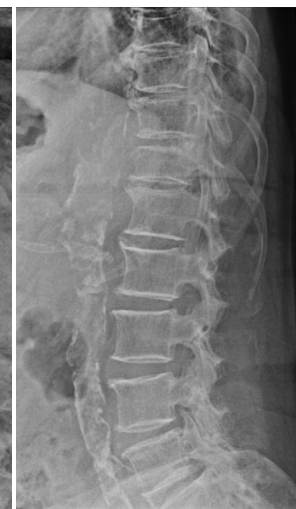

(b)

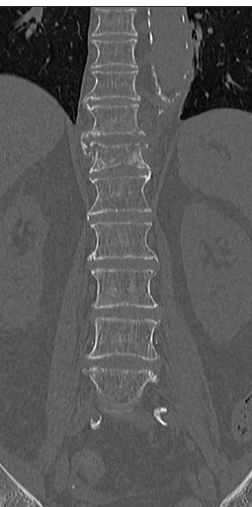

(c)

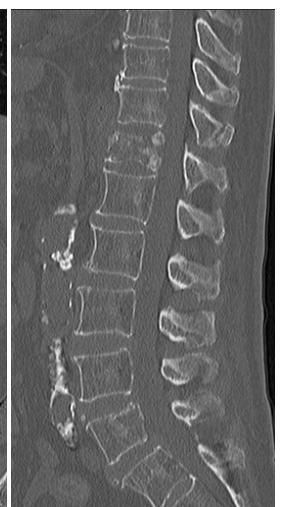

(d)

Figure 1. Preoperative plain radiograph and CT: Fracture of T12 vertebral, cleft formation (a) Anterior-Posterior (AP) view of a plain radiograph; (b) Lateral view of a plain radiograph; (c) CT coronal section; (d) CT sagittal section.

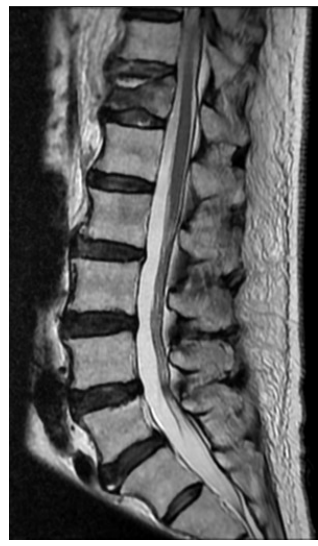

(a)

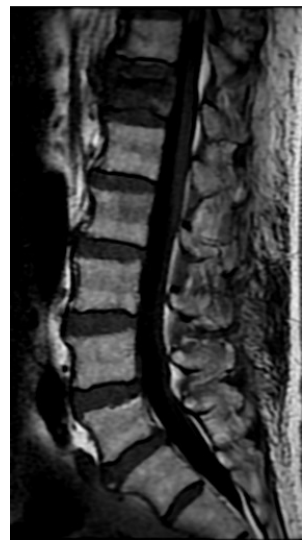

(b)

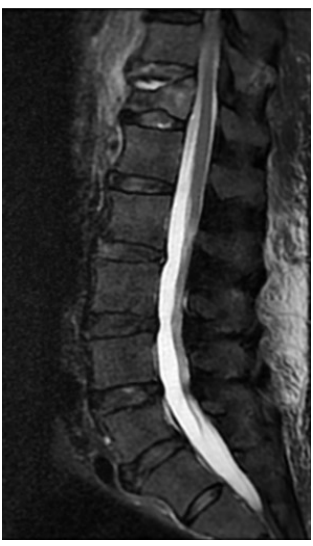

(c)

Figure 2. Preoperative MRI: T2WI-MRI and STIR-MRI showed confined high intensity inside the T12 vertebral (a) T2WI-MRI sagittal section; (b) T1WI-MRI sagittal section; (c) STIR-MRI sagittal section.

\subsection{Operation and Postoperative Course}

Even after conservative treatment was carried out, at the 1-month period following the onset of back pain, there was no improvement and the patient had difficulty getting out of bed. Therefore, T12 balloon kyphoplasty was performed in order to achieve early ambulation (Figure 3). Immediately after surgery, the back pain started to improve, and the patient was able to get out of bed, and at 1 month after surgery, she was transferred to a rehabilitation hospital. At two months after surgery, the back pain relapsed and the patient developed a fever of $38.4^{\circ} \mathrm{C}$; as a result, she was transferred to our department. The surgical wound showed no apparent abnormalities, but blood tests showed a CRP level of 3.46 $\mathrm{mg} / \mathrm{dL}$ and a WBC count as high as $9680 / \mu \mathrm{L}$ (Table 1); XP and CT findings showed a vertebral osteolysis of T11/12 and an anterior dislodgement of the T12 bone cement was also found (Figure 4). MRI showed abscess-like changes in T11/12 (Figure 5); therefore, the feasibility of balloon kyphoplasty was taken 


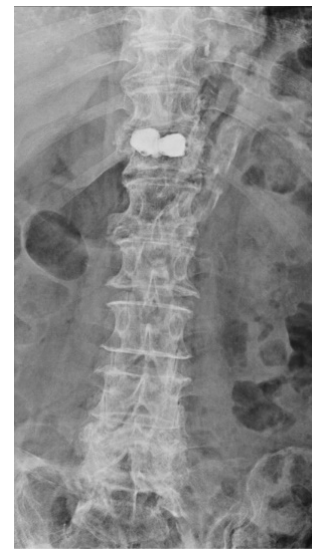

(a)

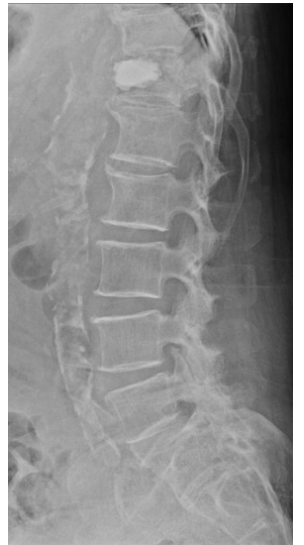

(b)

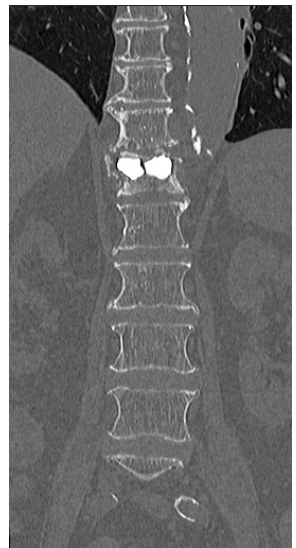

(c)

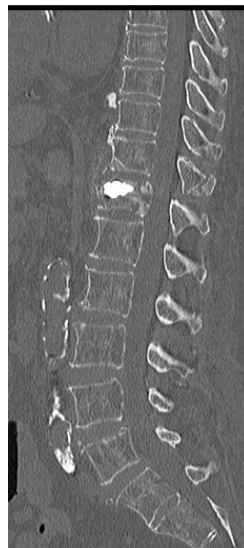

(d)

Figure 3. Postoperative plain radiograph and CT: T12 balloon kyphoplasty. (a) Anterior-Posterior (AP) view of a plain radiograph; (b) Lateral view of a plain radiograph; (c) CT coronal section; (d) CT sagittal section.

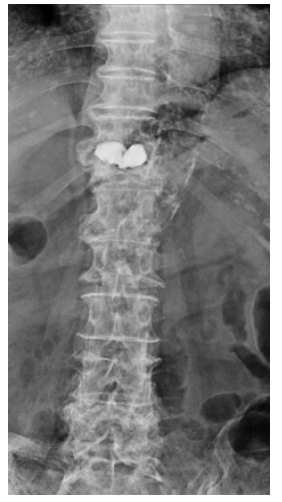

(a)

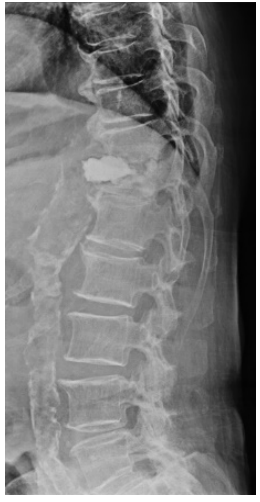

(b)

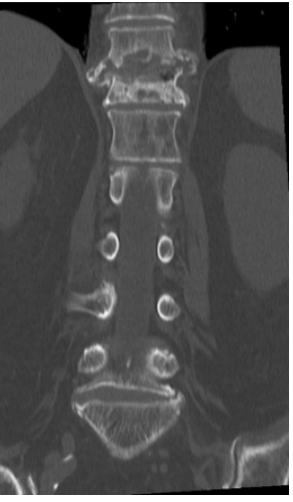

(c)

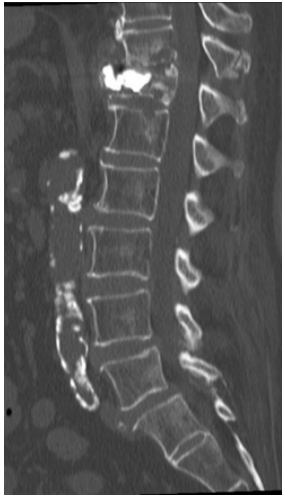

(d)

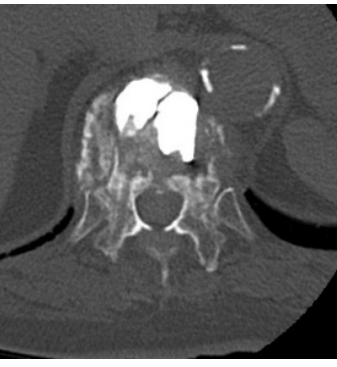

(e)

Figure 4. 2 months postoperative plain radiograph and CT: T11/12 showed vertebral osteolysis and T12 bone cement was anteriorly dislodged. (a) Anterior-Posterior (AP) view of a plain radiograph; (b) Lateral view of a plain radiograph; (c) CT coronal section; (d) CT sagittal section; (e) CT horizontal section.

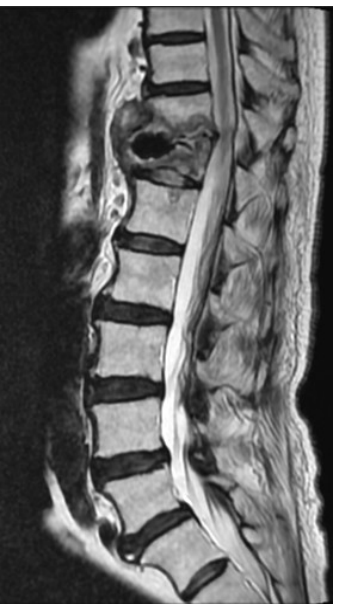

(a)

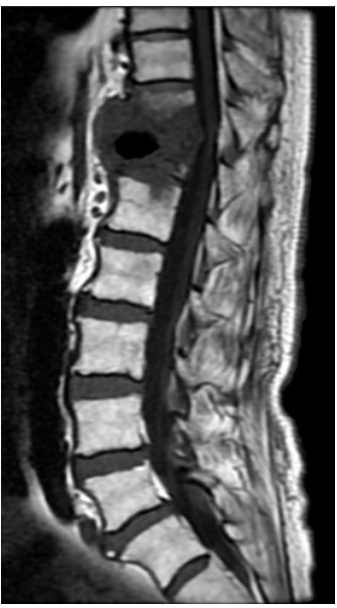

(b)

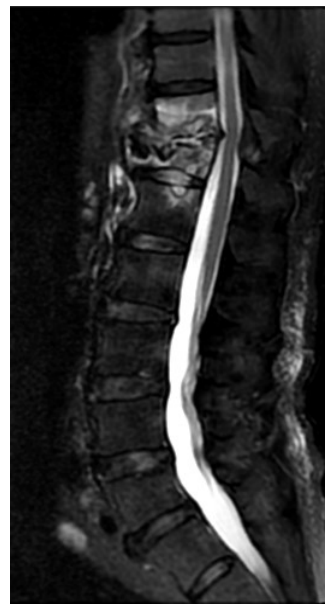

(c)

Figure 5. 2 months postoperative MRI: Abscess was found in T11/12. (a) T2WI-MRI sagittal section; (b) T1WI-MRI sagittal section; (c) STIR-MRI sagittal section. 
into consideration as a measure against vertebral collapse due to osteomyelitis of the thoracic spine or postoperative infection. There were no symptoms of paralysis, and early internal fixation was judged difficult or impossible because of glucocorticoid-induced osteoporosis. Therefore, the patient was first treated with antibiotics six weeks (Cefazolin 2 g every $8 \mathrm{hr}$ ), bed rest and teriparatide for approximately six weeks, after which efforts were made to resolve the infection and improve bone strength. At four months after balloon kyphoplasty, findings showed a normalization of CRP $(0.28 \mathrm{mg} / \mathrm{dL})$ and WBC $(7600 / \mu \mathrm{L})$ (Table 1$)$, the infection of T11/12 had resolved, and the anteriorly dislodged bone cement started to be covered by newly formed bone and showed a tendency towards bone union (Figure 6 and Figure 7). Later, posterior fusion (T9-L2) was performed

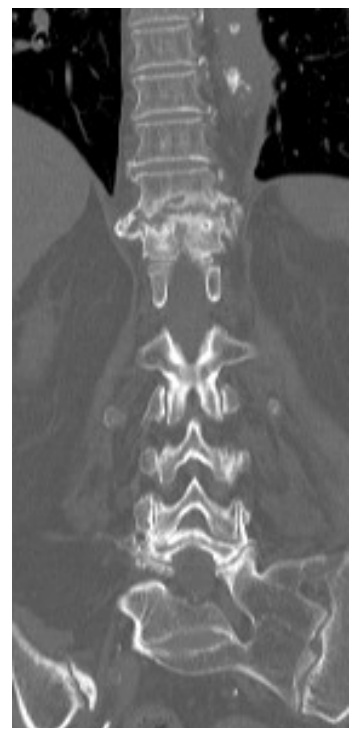

(a)

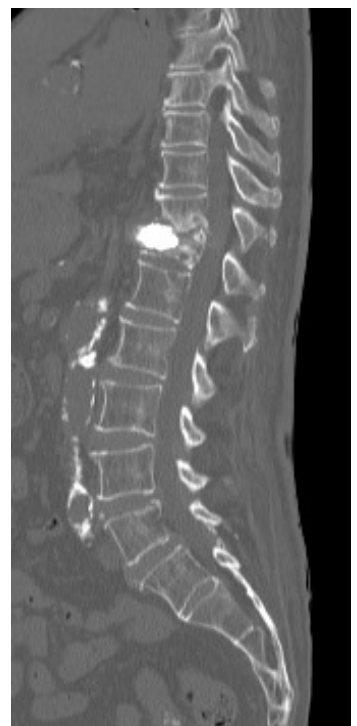

(b)

Figure 6. 4 months postoperative CT: Bone formation was shaped like an eggshell that covered the anteriorly dislodged bone cement. (a) CT coronal section; (b) CT sagittal section.

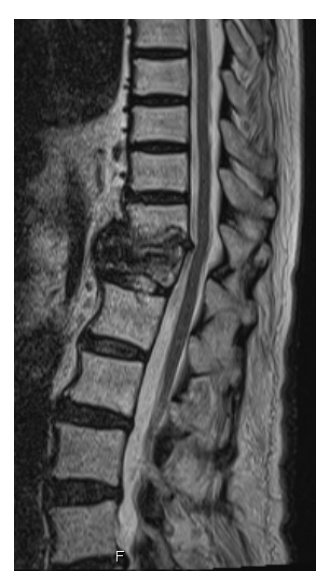

(a)

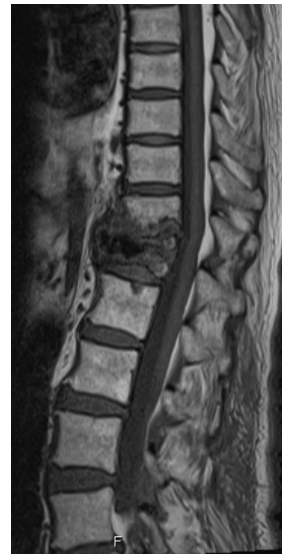

(b)

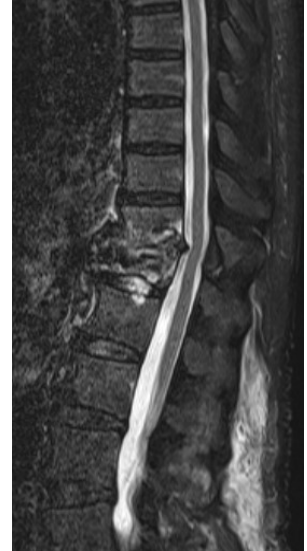

(c)

Figure 7. 4 months postoperative MRI: The abscess in T11/12 has resolved. (a) T2WI-MRI sagittal section; (b) T1WI-MRI sagittal section; (c) STIR-MRI sagittal section. 


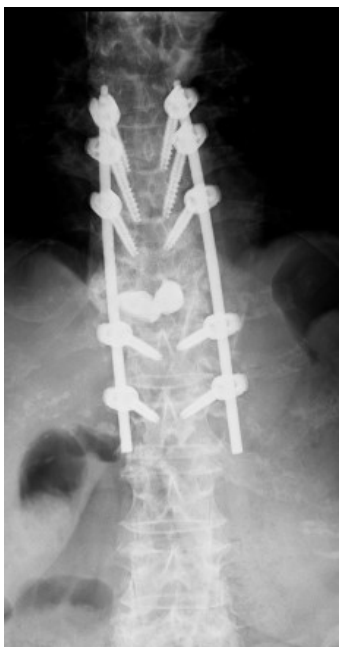

(a)

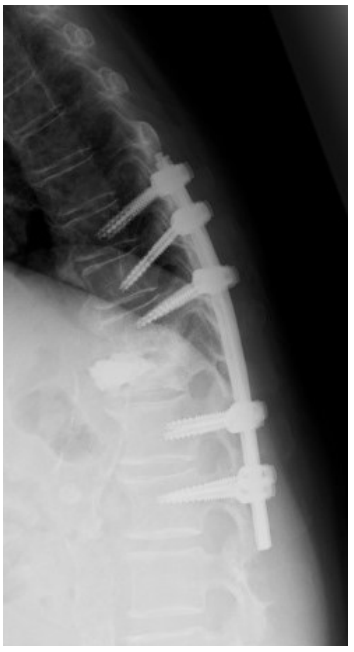

(b)

Figure 8. Postoperative plain radiograph: Posterior fusion: T9-L2 using percutaneous pedicle screws. (a) Anterior-Posterior (AP) view of a plain radiograph; (b) Lateral view of a plain radiograph.

using percutaneous pedicle screws (Figure 8). At 1 month after posterior fusion, CRP was $0.24 \mathrm{mg} / \mathrm{dL}$ and the $\mathrm{WBC}$ was $7900 / \mu \mathrm{L}$, showing that there was no relapse of infection. Furthermore, observations at two years after surgery showed a favorable clinical course.

\section{Discussion}

Balloon kyphoplasty is one of the treatment options for vertebral fractures with persistent pain, but nowadays, performing balloon kyphoplasty at an early stage after the occurrence of a vertebral fracture has become increasingly common, and there have occasionally been reports recommending early balloon kyphoplasty [1] [2] [3].

In the management of cases of osteoporotic vertebral fractures with poor pain improvement, performing balloon kyphoplasty at an early stage is also beneficial in terms of pain improvement, preservation of activities of daily living, and from the perspective of the prevention of complications through non-surgical means [4]. In the case reported in our study, no improvement was achieved even after the patient was subjected to conservative treatment for 1 month.

Certain imaging findings are considered factors of poor prognosis. For example, a confined high intensity or a wide area of low signal intensity in T2WI-MRI images is a risk factor for vertebral collapse and nonunion [5] [6] [7]. In addition, the presence of intravertebral clefts and posterior wall injury in plain radiographs and computed tomography (CT) scans has also been reported to be a factor of poor prognosis [8] [9]. In the case reported in our study, T2WI-MRI showed confined high intensity, and CT scan images showed intravertebral clefts; therefore, balloon kyphoplasty was carried out at an early stage.

Postoperative infection following balloon kyphoplasty is an extremely rare 
complication, and when postoperative infections do occur, they have a considerable impact on the vital prognosis. Thus, careful precautions must be taken, particularly in immunocompromised patients [10]. In one previous case report, balloon kyphoplasty was performed after pyogenic spondylitis failed to be diagnosed preoperatively, and it was during the postoperative course that pyogenic spondylitis was diagnosed [11].

Pyogenic spondylitis is an extremely important differential diagnosis of vertebral fracture. In the case reported in this study, CRP levels were mildly high in a chronic manner due to the effect of RS3PE syndrome. In addition, the patient had glucocorticoid-induced osteoporosis as well as diabetes, and her condition was complicated with pneumonia and a urinary tract infection. Therefore, differentiating between vertebral fracture and pyogenic spondylitis was extremely difficult in the early stages of the condition. As a result, when we take a retrospective look at the case reported in our study, it seems that balloon kyphoplasty was performed on a patient with early stage pyogenic spondylitis.

\section{Conclusion}

We experienced a case of a patient who was diagnosed with thoracic vertebral fracture and treated at a relatively early stage with balloon kyphoplasty, and who later developed an infection at the fracture site, which led to treatment difficulty. As balloon kyphoplasty tends to be performed at a relatively early stage nowadays, there can be cases that are diagnosed as vertebral fracture, but which are actually pyogenic spondylitis. When balloon kyphoplasty is performed on an immunocompromised patient with vertebral fracture at an early stage after sustaining an injury, the choice of treatment must be made with consideration of the possibility of latent pyogenic spondylitis.

\section{Acknowledgements}

All authors contributed to proofreading and editing the manuscript before submission.

\section{Ethics Approval and Consent to Participate}

We obtained the informed consent from the patient to report this case.

\section{Conflicts of Interest}

The authors declare no conflicts of interest regarding the publication of this paper.

\section{References}

[1] Minamide, A., Maeda, T., Yamada, H., Murakami, K., Okada, M., Enyo, Y., et al. (2018) Early Versus Delayed Kyphoplasty for Thoracolumbar Osteoporotic Vertebral Fractures: The Effect of Timing on Clinical and Radiographic Outcomes and Subsequent Compression Fractures. Clinical Neurology and Neurosurgery, 173, 176-181. https://doi.org/10.1016/j.clineuro.2018.07.019 
[2] Takahashi, S., Hoshino, M., Terai, H., Toyoda, H., Suzuki, A., Tamai, K., et al. (2018) Differences in Short-Term Clinical and Radiological Outcomes Depending on Timing of Balloon Kyphoplasty for Painful Osteoporotic Vertebral Fracture. Journal of Orthopaedic Science, 23, 51-56. https://doi.org/10.1016/j.jos.2017.09.019

[3] Mohammad, S.M., Ali, H., Fariborz, G. and Ghazal, I. (2017) Functional Recovery Following Early Kyphoplasty Versus Conservative Management in Stable Thoracuolumbar Fractures in Parachute Jumpers: A Randomized Clinical Trial. Clinical Spine Surgery, 30, E1066-E1073. https://doi.org/10.1097/BSD.0000000000000546

[4] Sakai, T. (2018) Is Early Stage Balloon Kyphoplasty for Osteoporotic Vertebral Fracture Appropriate? Journal of Spine Research, 9, 1719-1722.

[5] Takahashi, S., Hoshino, M., Takayama, K., Iseki, K., Sasaoka, R., Tsujio, T., et al. (2017) Time Course of Osteoporotic Vertebral Fractures by Magnetic Resonance Imaging Using a Simple Classification: A Multicenter Prospective Cohort Study. Osteoporosis International, 28, 473-482. https://doi.org/10.1007/s00198-016-3737-X

[6] Takahashi, S., Hoshino, M., Takayama, K., Iseki, K., Sasaoka, R., Tsujio, T., et al. (2016) Predicting Delayed Union in Osteoporotic Vertebral Fractures with Consecutive Magnetic Resonance Imaging in the Acute Phase: A Multicenter Cohort Study. Osteoporosis International, 27, 3567-3575.

https://doi.org/10.1007/s00198-016-3687-3

[7] Tsujio, T., Nakamura, H., Terai, H., Hoshino, M., Namikawa, T., Matsumura, A., et al. (2011) Characteristic Radiographic or Magnetic Resonance Images of Fresh Osteoporotic Vertebral Fractures Predicting Potential Risk for Nonunion: A Prospective Multicenter Study. Spine, 36, 1229-1235. https://doi.org/10.1097/BRS.0b013e3181f29e8d

[8] Jang, J.S., Kim, D.Y. and Lee, S.H. (2003) Efficacy of Percutaneous Vertebroplasty in the Treatment of Intravertebral Pseudarthrosis Associated with Noninfected Avascular Necrosis of the Vertebral Body. Spine, 28, 1588-1592. https://doi.org/10.1097/01.BRS.0000076824.61074.06

[9] Malghem, J., Maldague, B., Labaisse, M.A., Dooms, G., Duprez, T., Devogelaer, J.P., et al. (1993) Intravertebral Vacuum Cleft: Changes in Content after Supine Positioning. Radiology, 187, 483-487. https://doi.org/10.1148/radiology.187.2.8475295

[10] Abdelrahman, H., Siam, A.E., Shawky, A., Ezzati A. and Boehm H. (2013) Infection after Vertebroplasty or Kyphoplasty. A Series of Nine Cases and Review of Literature. Spine Journal, 13, 1809-1817. https://doi.org/10.1016/j.spinee.2013.05.053

[11] Pola, E., Autore, G., Pambianco, V., Formica, V.M., Colangelo, D. and Nasto, L.A. (2016) A Particular Case of Pyogenic Spondylodiscitis Misdiagnosed as a Vertebral Fragility Fracture and Erroneously Treated with Balloon Kyphoplasty. Spine Journal, 16, E659-E662. https://doi.org/10.1016/j.spinee.2016.02.047 